\title{
Gender Differences in Beliefs about Infant-Directed Speech: The Role of Family Dynamics
}

\author{
Shelia M. Kennison and Jennifer Byrd-Craven \\ Oklahoma State University, Stillwater, OK 74078, USA \\ Correspondence should be addressed to Shelia M. Kennison; shelia.kennison@okstate.edu
}

Received 16 August 2015; Accepted 5 October 2015

Academic Editor: Olga Capirci

Copyright ( 2015 S. M. Kennison and J. Byrd-Craven. This is an open access article distributed under the Creative Commons Attribution License, which permits unrestricted use, distribution, and reproduction in any medium, provided the original work is properly cited.

\begin{abstract}
The research investigated the relationship between family dynamics and the beliefs about the benefits of talking to infants. Prior research has shown that language development is enhanced by verbal interaction with others. We tested two hypotheses: (a) men may view talking to infants as less beneficial than women and (b) one's relationships with parents would be related to the extent to which young adults view talking to infants as beneficial. In a study with 301 undergraduates (181 women, 120 men), we confirmed both hypotheses, showing that (a) men were less likely than women to view talking to infants as beneficial and (b) for both men and women, the more negative their relationship with their mother, the less likely they were to view talking to infants as beneficial. Implications for infant care are discussed.
\end{abstract}

\section{Introduction}

There is now an abundance of research documenting the long-term benefits of talking to children [1-5]. Research suggests that differences in how much language children experience may explain language performance differences for children from different socioeconomic backgrounds [68]. In a recent study, Weisleder and Fernald [5] found that child-direct speech (CDS) was related to expressive vocabulary; infants' language processing efficiency mediated this relationship. The impetus for the present research was our observation that the view that talking to infants is beneficial for the infants' language development is not yet widely held among young adults. Our observations stem from conversations with students in our undergraduate courses in developmental psychology and language development. In the present research, we explore the beliefs held about infantdirected speech among young adults and investigate the extent to which family dynamics are related to those beliefs.

Prior research has shown that childrearing beliefs as well as beliefs about child development are related to parental behaviors $[9,10]$. Research also has shown that parenting behaviors are related to outcomes for children [11]. Donahue and colleagues have shown that mothers' beliefs are related to behaviors with children $[12,13]$; they found that mothers' language behaviors (e.g., questioning style and communication strategies) with children were predicted by mother's beliefs about how the environment affects child development; as belief that the environment plays an important role increased, the number of questions used by mothers with children increased. Research by Vernon-Feagans and colleagues has found that, in samples of mid-SES and low SES families, fathers' speech to children was correlated with their children's language development $[14,15]$.

In the literature investigating parental beliefs across cultures, researchers have speculated that parental beliefs may relate to other aspects of the home environment. Chao [16] asserts that parental beliefs shape child development broadly, determining more than just parent-child verbal interactions; beliefs may also relate to the organization of the living environment as well as the priorities emphasized by the family. Rodriguez and Olswang [17] investigated Mexican-American mothers' beliefs that the language delays in their children involved external forces, such as God's will or the environment. Kummerer and Lopez-Reyna [18] interviewed 14 Mexican-American immigrant mothers about their children's speech problems, which were being addressed in speech therapy. Mothers frequently cited the home environment as 
an important factor in their children's language development. Research on how parents view children's development of literacy skills has shown that that while some mothers view their role as facilitative and engage in home-based readingrelated activities with children, other mothers believe that it is the role of the school, rather than their own, to teach children the literacy skills they need [19].

Some researchers have recognized the value of assessing beliefs about child language development. Donahue et al. [20] developed a scale to measure theory-based beliefs about child language development. The scale was composed of four subscales, each representing a theoretical perspective on language development: (a) behaviorist, (b) cognitive, (c) nativist, and (d) sociolinguistic. The questions for each subscale were constructed following a content analysis of the relevant descriptions of language development theories in introductory textbooks on language development. In a sample of 308 female college students, they found that the behaviorist beliefs were most frequently endorsed. Sociolinguistic beliefs varied significantly by ethnicity. White participants endorsed sociolinguistic beliefs (e.g., "talking to a child is important even if he/she does not understand") more often than African-American and Latina participants. Cognitive beliefs differed significantly for monolingual and bilingual participants. Bilingual participants endorsed cognitive beliefs (e.g., "parents need to adapt their speech to how much their children understand") more often than monolingual participants. A potential criticism of the scale is that some of the subscale questions appear only loosely connected to the theoretical perspective.

In the present research, we set out to assess beliefs about the benefit of infant-directed speech held by young men and women. We anticipated that men and women would likely differ in their beliefs about the usefulness of talking to infants. Although there are few studies demonstrating gender differences in beliefs about infant-directed speech [3], there are numerous studies showing differences in how mothers and fathers interact with children. For example, some studies have found that the amount that fathers and mothers talk to their children differs; fathers talk less ([21-23] (cf. [24])). Abkarian et al. [25] found that fathers vary the pitch of their voices less than mothers (cf. [26]). Tenenbaum and Leaper [27] found that fathers were less aware of the cognitive abilities of their children than mothers were. Other studies have shown that fathers use different types of utterances than mothers. For example, when speaking with children, fathers' speech contains more directives (e.g., pick that up) than mothers $[23,28,29]$. Studies have also found that fathers ask children to clarify their utterances more than mothers and use more wh-questions than mothers [28]. Other research has found that fathers, more often than mothers, experienced breakdowns in communications when talking with children [30].

Based on research by Belsky and colleagues, we also hypothesized that women's and men's beliefs about the benefits of talking to infants would be related to their relationships with their own parents. Prior research has shown that family dynamics play a role in many outcomes for children [31, 32], including the timing of menarche, reproductive strategies, social cognitions, and adult attachment styles. When parentchild relationships that are negative, are inconsistent, have high conflict, or have high levels of stress, children tend to mature earlier, have children earlier, and develop adult attachments that are insecure [33]. In contrast, when parentchild relationships involve warmth and positive support, children tend to mature later, delay child-bearing, and develop adult attachments that are secure. Freitag et al. [34] found that parent-child communication plays a role the ability of children to form friendships later in childhood.

For the present investigation, we report the results of a study in which we explored the possibility that men and women differ in their beliefs about the benefits of talking to infants and the possibility that such beliefs are influenced by family dynamics, specifically aspects of their relationships with their own parents. We asked men and women to provide information about their beliefs about the value of infantdirected speech and about their dynamics with their parents. Because prior research has shown that fathers and mothers behave differently with children and past research with mothers demonstrates that parenting behaviors are linked to beliefs, we expected to find that women, to a greater extent than men, would view infant-directed speech as beneficial to infants. We also expected to find that positive aspects of the relationships with parents would be related to both women and men being more likely to develop beliefs that talking to infants is beneficial. In contrast, we expected to find that negative aspects of the relationships with parents would be related to women and men being less likely to develop beliefs that talking to infants is beneficial for infants.

\section{Method}

2.1. Participants. Three hundred and three undergraduates (181 women, 120 men) enrolled in psychology and speech courses at a large public university in the Midwest region of the United States participated in exchange for course credit. The average age of participants was $19.33(\mathrm{SD}=3.14)$. Seventynine percent of the sample was White, not of Hispanic origin; $6 \%$ was Hispanic; $4 \%$ was African-American; $4 \%$ was Native American; $4 \%$ belonged to more than one category; $2 \%$ was Asian American; and $1 \%$ was other. Participants were asked to describe the relationship with their primary male and female caregivers. For both men and women, 89 percent reported that their primary male caregiver was their biological father; 8 percent reported having no primary male caregiver. For women, 96 percent reported that their primary female caregiver was their biological mother; 3 percent reported having no primary female caregiver. For men, 93 percent reported that their primary female caregiver was their biological mother; less than 1 percent reported that they had no primary female caregiver.

2.2. Materials. The items on the perceptions of infant communication questionnaire were examined. The questionnaire is provided in the appendix. Items numbers $1,3,6,9,11$, and 14 had significant correlations above .40 and good reliability $(\alpha=.79)$. Due to the nature of the items and their association, they were combined into a single composite variable, 
Beneficial Beliefs, reflecting beliefs that communicating with preverbal infants is beneficial for their development. Items numbers 2 and 8 were significantly correlated $(r=.41$, $p<.01)$ and reflect beliefs about infants being passive in their development and were combined into a composite variable, Passive Infant $(\alpha=.58)$. Finally, items 12 and 13 were significantly correlated $(r=.42, p<.01)$ and reflected family belief systems about drawbacks of talking to infants and so were labeled Family $(\alpha=.59)$. Beneficial Beliefs and Passive Infant were negatively correlated $(r=-.58, p<.01)$, as expected, and Passive Infant and Family were positively correlated $(r=.14, p<.05)$, also as expected.

We assessed family dynamics using the six dimensions of parenting questionnaire [35]; the instrument assesses relationships with mothers and fathers separately. Instructions were given to answer the questions based on their relationship with that parent growing up as well as their current relationship. The questionnaire has six major factors: warmth (e.g." "my father and I do special things together," $\alpha=.79$ ), structure (e.g." "my mother's expectations for me are clear," $\alpha=.65$ ), autonomy support (e.g. "my father expects me to say what I really think," $\alpha=.75$ ), rejection (e.g., "sometimes I feel like my mother thinks I'm difficult to like," $\alpha=.71$ ), chaos (e.g., "my father changes the rules a lot at home," $\alpha=.67$ ), and coercion (e.g., "I often get into power struggles with my mother," $\alpha=.77$ ). Composite variables were created for each parent from warmth, structure, and autonomy support (Positive Mother and Positive Father; $\alpha=$ .88 and $\alpha=.83$, resp.), following Byrd-Craven et al. [36]. Similarly, rejection, chaos, and coercion were combined to create Negative Mother $(\alpha=.85)$ and Negative Father $(\alpha=$ .84) variables.

2.3. Procedure. Participants completed the same survey online; they were recruited from the Department of Psychology SONA human participant scheduling software. Survey responses were collected using a professional license of SurveyMonkey. Participants responded to questions about beliefs about infant-directed speech before questions about family dynamics. Demographic questions were placed at the end of the survey.

\section{Results}

Descriptive statistics for the variables of interest were calculated for women and men. These variables were the three composite variables related to beliefs about infantdirected speech (i.e., Beneficial Beliefs, Passive Infant, and Family) and the four family dynamic composite variables (i.e., Positive Mother, Negative Mother, Positive Father, and Negative Father). Table 1 displays the summary of these results. Women and men differed significantly for the three composite variables related to beliefs about talking to infants. Women, more than men, believed that talking to infants is beneficial for the infant, $t(291)=5.64, p<.001$. Men, more than women, believed that infants are passive, $t(297)=4.93$, $p<.001$. Men, more than women, indicated that in their families talking to infants is discouraged, $t(299)=2.66$, $p<.001$. Men reported higher levels of negative father
TABLE 1: Descriptive statistics for dependent variables for women and men.

\begin{tabular}{lcccccccc}
\hline \multirow{2}{*}{ Variable } & \multicolumn{4}{c}{ Women } & \multicolumn{4}{c}{ Men } \\
& Mean & SD & Min & Max & Mean & SD & Min & Max \\
\hline Beneficial Beliefs & 5.83 & .94 & 2.50 & 7.00 & 5.17 & 1.04 & 2.83 & 7.00 \\
Passive Infant & 2.23 & 1.13 & 1.00 & 6.00 & 2.92 & 1.25 & 1.00 & 6.50 \\
Family & 3.06 & 1.37 & 1.00 & 7.00 & 3.47 & 1.26 & 1.00 & 7.00 \\
Positive Mother & 10.74 & 1.76 & 3.00 & 15.00 & 10.12 & 1.71 & 5.25 & 13.75 \\
Negative Mother & 5.67 & 2.63 & 3.00 & 15.00 & 6.22 & 2.60 & 5.25 & 13.00 \\
Positive Father & 9.86 & 2.59 & 3.00 & 15.00 & 9.66 & 1.99 & 3.00 & 15.00 \\
Negative Father & 6.27 & 3.11 & 3.00 & 15.00 & 6.57 & 2.88 & 3.00 & 15.00 \\
\hline
\end{tabular}

interactions than women, $t(288)=1.99, p<.05$. Women reported higher levels of positive mother interactions than men, $t(295)=2.50, p<.05$, and lower levels of negative mother interactions than men $t(297)=2.68, p<.01$. There were no other significant differences in the means for men and women, $t \mathrm{~s}<1$.

Correlations were conducted to explore the interrelatedness of the seven key variables. Table 2 displays a summary of these correlations overall and for men and women separately. We then conducted a series of multiple regression analyses to determine whether dimensions of parenting were predictive of Beneficial Beliefs. We limited our analysis to Beneficial Beliefs because of the relatively low reliability of the two other belief variables (i.e., Passive Infant and Family beliefs). Regarding Beneficial Beliefs, we reasoned that family dynamics may be related to beliefs differently for women and men, so all analyses were run separately by gender. Table 3 provides a summary of the results. The overall models were significant for men, $F(4,110)=10.16, p<.001$, and adjusted $R^{2}=.25$, and women, $F(4,166)=6.96, p<.001$, and adjusted $R^{2}=.13$. For both men and women, Negative Mother emerged as the only significant predictor: men, $\beta=.45, p<.001$, and women, $\beta=-.25, p=.01$.

Additional tests were carried out to determine whether the correlations, slopes, and intercepts of the regression lines for the relationship between negative mother and Beneficial Beliefs differed for men and women. No significant differences were observed.

\section{Discussion}

In the present research, we investigated the relationships between beliefs about infant-directed speech and family dynamics. We hypothesized that participants' positive relationships with mothers and fathers would be related to higher levels of belief that infant-directed speech is beneficial to infants and that participants' negative relationships with mothers and fathers would be related to lower levels of the same beliefs. The results showed that, for both men and women, only Negative Mother interactions predicted levels of belief that infant-directed speech is beneficial for infants. Higher levels of Negative Mother interactions were related to lower levels of belief that infant-directed speech is beneficial for infants. Having a negative relationship with one's mother may affect one's beliefs about what constitutes 
TABLE 2: Summary of correlational results overall (men, women).

\begin{tabular}{|c|c|c|c|c|c|c|}
\hline & 1 & 2 & 3 & 4 & 5 & 6 \\
\hline \multicolumn{7}{|l|}{ (1) Beneficial Beliefs } \\
\hline (2) Passive Infant & $-.58(-.54,-54)$ & & & & & \\
\hline (3) Family & $-.08(.01,-.07)$ & $.14(-.04, .21)$ & & & & \\
\hline (4) Positive Mother & $.14(.26, .00)$ & $-.02(-.09, .10)$ & $.04(.09, .03)$ & & & \\
\hline (5) Negative Mother & $-.46(-.51,-.42)$ & $.33(.40, .26)$ & $.14(.12, .13)$ & $.03(-.29,-.09)$ & & \\
\hline (6) Positive Father & $.13(.23, .08)$ & $-.05(-.15, .01)$ & $.05(.10, .03)$ & $.40(.46, .35)$ & $.03(-.14, .10)$ & \\
\hline (7) Negative Father & $-.34(-.37,-.32)$ & $.22(.23, .20)$ & $.13(.12, .13)$ & $-.04(-.28, .06)$ & $.64(.69, .56)$ & $.06(-.08,-.08)$ \\
\hline
\end{tabular}

Note: bold correlations are significant at $p<.05$.

TABLE 3: Summary of multiple regression results for men and women with family dynamics variables predicting Beneficial Beliefs.

\begin{tabular}{lcccccc}
\hline \multirow{2}{*}{ Predictors } & \multicolumn{3}{c}{ Men } & \multicolumn{3}{c}{ Women } \\
& $B$ & SE & $\beta$ & $B$ & SE & $\beta$ \\
\hline Intercept & 4.99 & .72 & - & 6.36 & .59 & - \\
Negative Mother & -.18 & .05 & $-.45^{* *}$ & -.10 & .04 & $-.16^{*}$ \\
Positive Mother & .04 & .06 & .06 & .01 & .05 & .01 \\
Negative Father & .01 & .01 & .03 & -.07 & .04 & -.16 \\
Positive Father & .09 & .06 & .16 & .04 & .03 & .09 \\
$R^{2}$ & .53 & & & .38 & & \\
Adjusted $R^{2}$ & .25 & & & .13 & & \\
\hline
\end{tabular}

Note: one asterisk indicates $p<.01$; two asterisks indicate $p<.001$.

a typical mother-child interaction. Those with more negative relationships with their mothers may adopt a view of adequate parenting that involves less verbal interaction with infants than others. The results are consistent with prior research emphasizing the role of mother-child interactions in children's future social behaviors [34].

These results are consistent with previous work that suggests that early parent-child interactions set developmental trajectories associated with a suite of characteristics including reproductive strategies, and parenting style [31]. Attitudes toward talking to infants may reflect a larger schema regarding investing in the sociocognitive competencies of infants and children in general. Harsh or inconsistent mothers in particular may serve as a cue regarding the perceived benefits of investing in infants' developing cognition overall. Our results suggest that these attitudes are intergenerationally transmitted, which provides an important intervention point-changing the beliefs of new mothers regarding infant-directed speech is likely to change the language learning outcomes both for her child and also for her future grandchild.

As expected, the results showed some evidence of gender differences in beliefs about infant-directed speech. Women reported believing that infant-directed speech is beneficial for infants more than men did. Men reported believing that infants are passive more than women did. Men reported that their families did not encourage talking to infants more than women did. Women also reported higher levels of positive mother interactions than men did. However, the average level of Negative Mother interactions reported did not differ significantly for men and women. Importantly, for the central finding that Negative Mother interaction significantly predicted Beneficial Beliefs, there was no gender difference, as Negative Mother predicted Beneficial Beliefs for both men and women, and the correlations and regression line slopes and intercepts did not differ significantly between men and women.

The study was an exploratory study, as there have been few investigations of beliefs about infant-directed speech. The limitations of the study include the fact that our sample of participants was predominantly White. Furthermore, most participants reported having relationships with their biological parents. It is possible that the relationship beliefs about infant-directed speech and Negative Mother interactions would be different from the present results for a sample in which participants' primary caregiver is not one's biological mother but is instead a grandmother, aunt, and stepmother. Of particular interest would be investigating the predictors of beliefs about infant-direct speech in a sample of individuals who were not raised with a primary female caregiver. We also suspect that beliefs about infant-directed speech may vary across cultural groups related to race and/or ethnicity, country of origin, and religious affiliations. We also note that parents and other caregivers may adapt their communications to infants in a way that is automatic and that these adaptations may be beneficial for infants. Such adaptations are less likely to be tied to individuals' beliefs about infant care than consciously performed behaviors. It is possible that beliefs about infant care would be related to both conscious and unconscious adaptations that caregivers make; however, we would expect that the link between beliefs and behavior would be stronger conscious versus unconscious adaptations.

The present results and the limitations of the research provide directions for future research. Future work is needed to examine how the questions about the benefits of infantdirected speech are related to existing scales designed to measure beliefs about child language development (e.g., [20]). Such work may be able to identify a relatively small set of questions to make up a psychometrically rigorous instrument that could then be used in a study investigating how beliefs about infant-directed speech predict parental behavior with infants. The long-term benefit of this program of research would be to then use the infant-directed speech belief scale to identify individuals caring for infants who may benefit from short-term educational programs explaining 
how infant-directed speech aids in the development of infant sensory, cognitive, and language systems and how early exposure to language can benefit language development during the toddler years and beyond.

The present results have implications for those involved in the care of infants. We find it noteworthy that participants in our study who expressed a high level of belief that infant-directed speech was beneficial for infants reported that they had learned about infant-directed speech in a college course (e.g., developmental psychology and language development). In these courses, students learn about aspects of fetal development that are related to hearing and memory, such as the fact that fetuses are able to hear sounds external to the womb and form memories of those sounds [3]. Furthermore, during the first year of life, infants' perceptual abilities for distinguishing speech sounds change. At birth, infants are able to distinguish all speech sounds from all human languages. By the end of the first year, infants are able to distinguish only those speech sounds that they have experienced regularly in daily life. Individuals with less than a college education may not have easy access to these important facts about infant development.

\section{Appendix}

The following fourteen items were constructed for the study and used with a 7 -point scale $(1=$ strongly disagree, $7=$ strongly agree). The items were grouped into three composite variables: Beneficial Beliefs (1, 3, 6, 9, 11, and 14), Passive Infant (2 and 8 ), and Family (12 and 13). Four items were reverse scored (i.e., 2, 4, 5, and 11).

(1) Talking to an infant is helpful to them regardless of the infant's age.

(2) Talking to an infant is not helpful if the infant is very young.

(3) Talking to an infant may help in their development of language.

(4) When one is holding an infant, it is best to be silent as much as possible.

(5) An infant's brain is not able to learn very much until after 12 months of age.

(6) Infants benefit from listening to the speech of adults even if they cannot understand what is being said.

(7) When I am around an infant, I tend to use facial expressions to connect with the infant.

(8) When one is holding an infant, it is best to talk as much as possible.

(9) When I am around a toddler, I tend to talk to him or her.

(10) Infants are sponges that soak up everything they are exposed to in the environment.

(11) Infants generally cannot understand language before they begin speaking around the age of 12 to 14 months.

(12) In my family, using baby talk with infants is discouraged.
(13) In my family, we talk to children the same way that we talk to adults.

(14) Using baby talk when talking to an infant may be helpful to the infant.

\section{Conflict of Interests}

The authors declare that there is no conflict of interests regarding the publication of this paper.

\section{References}

[1] N. Hurtado, V. A. Marchman, and A. Fernald, "Does input influence uptake? Links between maternal talk, processing speed and vocabulary size in Spanish-learning children," Developmental Science, vol. 11, no. 6, pp. F31-F39, 2008.

[2] J. Huttenlocher, W. Haight, A. Bryk, M. Seltzer, and T. Lyons, "Early vocabulary growth: relation to language input and gender," Developmental Psychology, vol. 27, no. 2, pp. 236-248, 1991.

[3] S. M. Kennison, Introduction to Language Development, Sages, Los Angeles, Calif, USA, 2013.

[4] M. L. Rowe, "A longitudinal investigation of the role of quantity and quality of child-directed speech in vocabulary development," Child Development, vol. 83, no. 5, pp. 1762-1774, 2012.

[5] A. Weisleder and A. Fernald, "Talking to children matters: early language experience strengthens processing and builds vocabulary," Psychological Science, vol. 24, no. 11, pp. 2143-2152, 2013.

[6] J. Huttenlocher, H. Waterfall, M. Vasilyeva, J. Vevea, and L. V. Hedges, "Sources of variability in children's language growth," Cognitive Psychology, vol. 61, no. 4, pp. 343-365, 2010.

[7] B. A. Pan, M. L. Rowe, J. D. Singer, and C. E. Snow, "Maternal correlates of growth in toddler vocabulary production in lowincome families," Child Development, vol. 76, no. 4, pp. 763-782, 2005.

[8] M. L. Rowe, "Child-directed speech: relation to socioeconomic status, knowledge of child development and child vocabulary skill," Journal of Child Language, vol. 35, no. 1, pp. 185-205, 2008.

[9] J. J. Goodnow and W. A. Collins, Development According to Parents: The Nature, Sources, and Consequences of Parents' Ideas, Lawrence Erlbaum Associates, Hillsdale, NJ, USA, 1990.

[10] I. E. Sigel, Parental Belief Systems: The Psychological Consequences for Children, Lawrence Erlbaum Associates, Hillsdale, NJ, USA, 1985.

[11] A. V. McGillicuddy-DeLisi and I. E. Sigel, "Parental beliefs," in Handbook of Parenting, M. H. Bornstein, Ed., vol. 3, pp. 333-358, Lawrence Erlbaum Associates, Hillsdale, NJ, USA, 1995.

[12] M. L. Donahue and R. Pearl, "Conversational interactions of mothers and their preschool children who had been born preterm," Journal of Speech and Hearing Research, vol. 38, no. 5, pp. 1117-1125, 1995.

[13] M. L. Donahue, R. Pearl, and A. Herzog, "Mothers' referential communication with preschoolers: effects of children's syntax and mothers' beliefs," Journal of Applied Developmental Psychology, vol. 18, no. 1, pp. 133-147, 1997.

[14] N. Pancsofar and L. Vernon-Feagans, "Mother and father language input to young children: contributions to later language development," Journal of Applied Developmental Psychology, vol. 27, no. 6, pp. 571-587, 2006. 
[15] N. Pancsofar, L. Vernon-Feagans, and The Family Life Project Investigators, "Fathers' early contributions to children's language development in families from low-income rural communities," Early Childhood Research Quarterly, vol. 25, no. 4, pp. 450-463, 2010.

[16] R. K. Chao, "Chinese and European American mothers' beliefs about the role of parenting in children's school success," Journal of Cross-Cultural Psychology, vol. 27, no. 4, pp. 403-423, 1996.

[17] B. L. Rodriguez and L. B. Olswang, "Mexican-American and Anglo-American mothers' beliefs and values about child rearing, education, and language impairment," American Journal of Speech-Language Pathology, vol. 12, no. 4, pp. 452-462, 2003.

[18] S. E. Kummerer and N. A. Lopez-Reyna, “The role of Mexican immigrant mothers' beliefs on parental involvement in speechlanguage therapy," Communication Disorders Quarterly, vol. 27, no. 2, pp. 83-94, 2006.

[19] D. J. Weigel, S. S. Martin, and K. K. Bennett, "Mothers' literacy beliefs: connections with the home literacy environment and pre-school children's literacy development," Journal of Early Childhood Literacy, vol. 6, no. 2, pp. 191-211, 2006.

[20] M. L. Donahue, Q. Fu, and E. V. Smith Jr., "Beliefs about language development: construct validity evidence," Journal of Applied Measurement, vol. 13, no. 4, pp. 336-359, 2012.

[21] R. G. Davidson and C. E. Snow, "Five-year-olds' interactions with fathers versus mothers," First Language, vol. 16, no. 47, pp. 223-242, 1996.

[22] B. McLaughlin, D. White, T. McDevitt, and R. Raskin, "Mothers' and fathers' speech to their young children: similar or different?" Journal of Child Language, vol. 10, no. 1, pp. 245-252, 1983.

[23] J. A. Rondal, "Fathers' and mothers' speech in early language development," Journal of Child Language, vol. 7, no. 2, pp. 353$369,1980$.

[24] K. Walker and L. Armstrong, "Do mothers and fathers interact differently with their child or is it the situation which matters?" Child: Care, Health and Development, vol. 21, no. 3, pp. 161-181, 1995.

[25] G. G. Abkarian, J. P. Dworkin, and A. K. Abkarian, "Father's speech to their children: perfect pitch or tin ear?" Fathering, vol. 1, no. 1, pp. 27-50, 2003.

[26] A. Warren-Leubecker and J. N. Bohannon III, "Intonation patterns in child-directed speech: mother-father differences," Child Development, vol. 55, pp. 1379-1385, 1984.

[27] H. R. Tenenbaum and C. Leaper, "Gender effects on Mexicandescent parents' questions and scaffolding during toy play: a sequential analysis," First Language, vol. 18, no. 53, pp. 129-147, 1998.

[28] M. L. Rowe, D. Coker, and B. A. Pan, "A comparison of fathers' and mothers' talk to toddlers in low-income families," Social Development, vol. 13, no. 2, pp. 278-291, 2004.

[29] M. Kornhaber and H. Marcos, "Young children's communication with mothers and fathers: functions and contents," British Journal of Developmental Psychology, vol. 18, no. 2, pp. 187-210, 2000.

[30] M. Tomasello, G. Conti-Ramsden, and B. Ewert, "Young children's conversations with their mothers and fathers: differences in breakdown and repair," Journal of Child Language, vol. 17, no. 1, pp. 115-130, 1990.

[31] J. Belsky, J. Sligo, S. R. Jaffee, L. Woodward, and P. A. Silva, "Intergenerational transmission of warm-sensitive-stimulating parenting: a prospective study of mothers and fathers of 3-yearolds," Child Development, vol. 76, no. 2, pp. 384-396, 2005.
[32] J. Belsky, R. M. Houts, and R. M. P. Fearon, "Infant attachment security and the timing of puberty: testing an evolutionary hypothesis," Psychological Science, vol. 21, no. 9, pp. 1195-1201, 2010.

[33] J. Belsky, L. Steinberg, and P. Draper, "Childhood experience, interpersonal development, and reproductive strategy: and evolutionary theory of socialization," Child Development, vol. 62, no. 4, pp. 647-670, 1991.

[34] M. K. Freitag, J. Belsky, K. Grossmann, K. E. Grossmann, and H. Scheuerer-Englisch, "Continuity in parent-child relationships from infancy to middle childhood and relations with friendship competence," Child Development, vol. 67, no. 4, pp. 1437-1454, 1996.

[35] E. Skinner, S. Johnson, and T. Snyder, "Six dimensions of parenting: a motivational model," Parenting: Science and Practice, vol. 5, no. 2, pp. 175-235, 2005.

[36] J. Byrd-Craven, B. J. Auer, D. A. Granger, and A. R. Massey, "The father-daughter dance: the relationship between fatherdaughter relationship quality and daughters' stress response," Journal of Family Psychology, vol. 26, no. 1, pp. 87-94, 2012. 

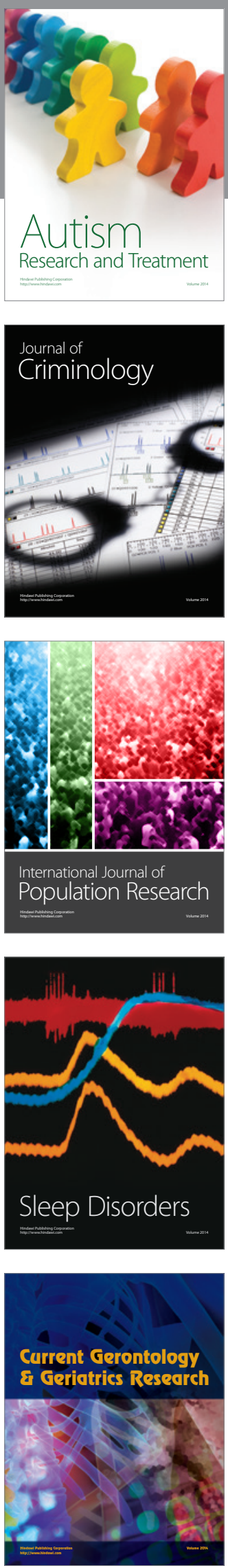
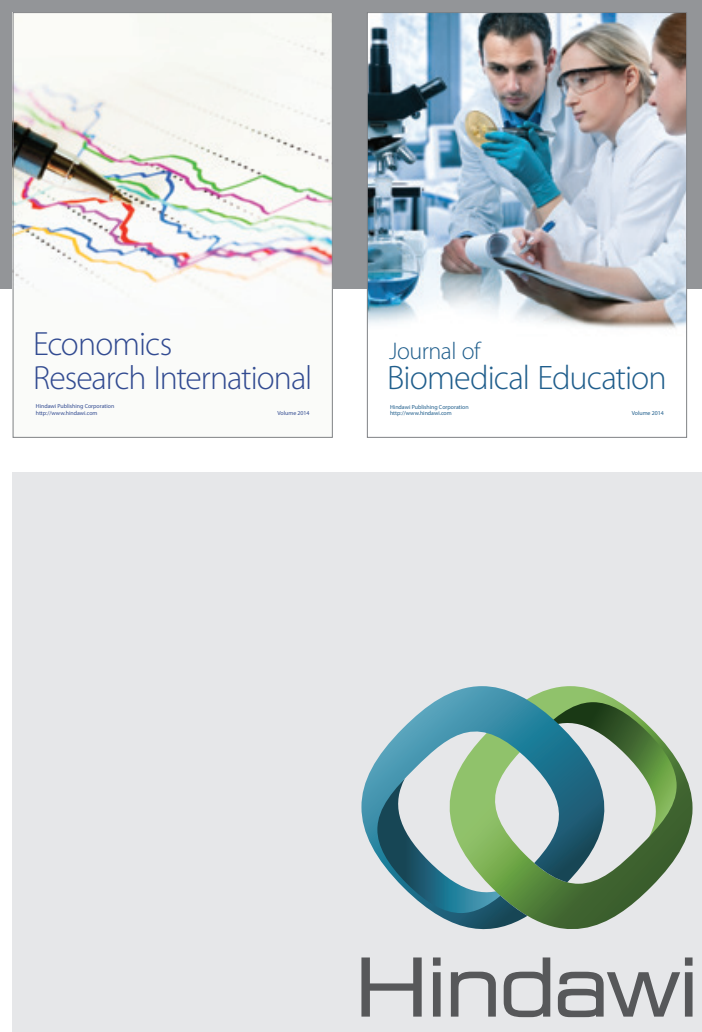

Submit your manuscripts at

http://www.hindawi.com
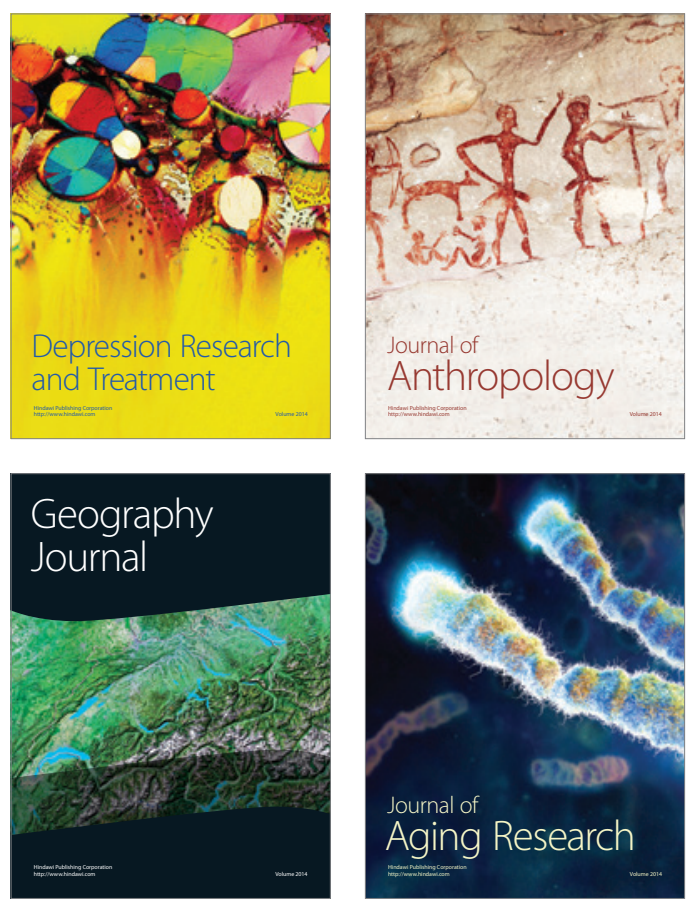
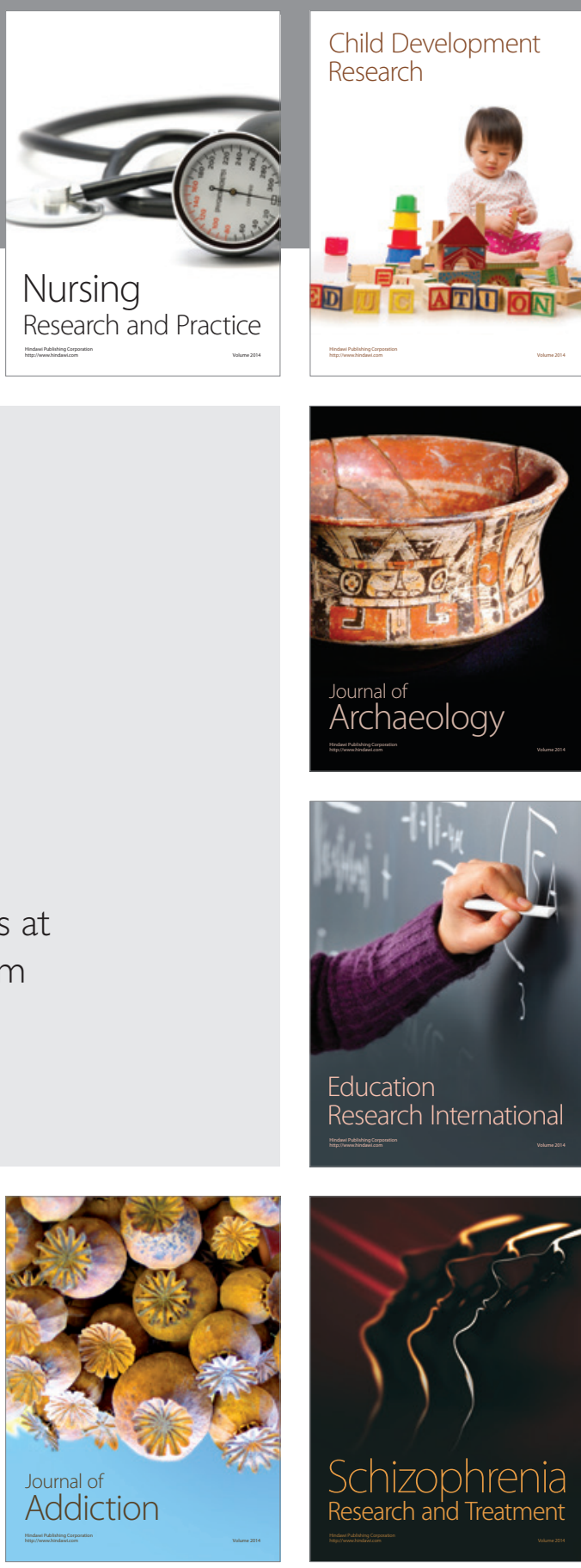

(D)
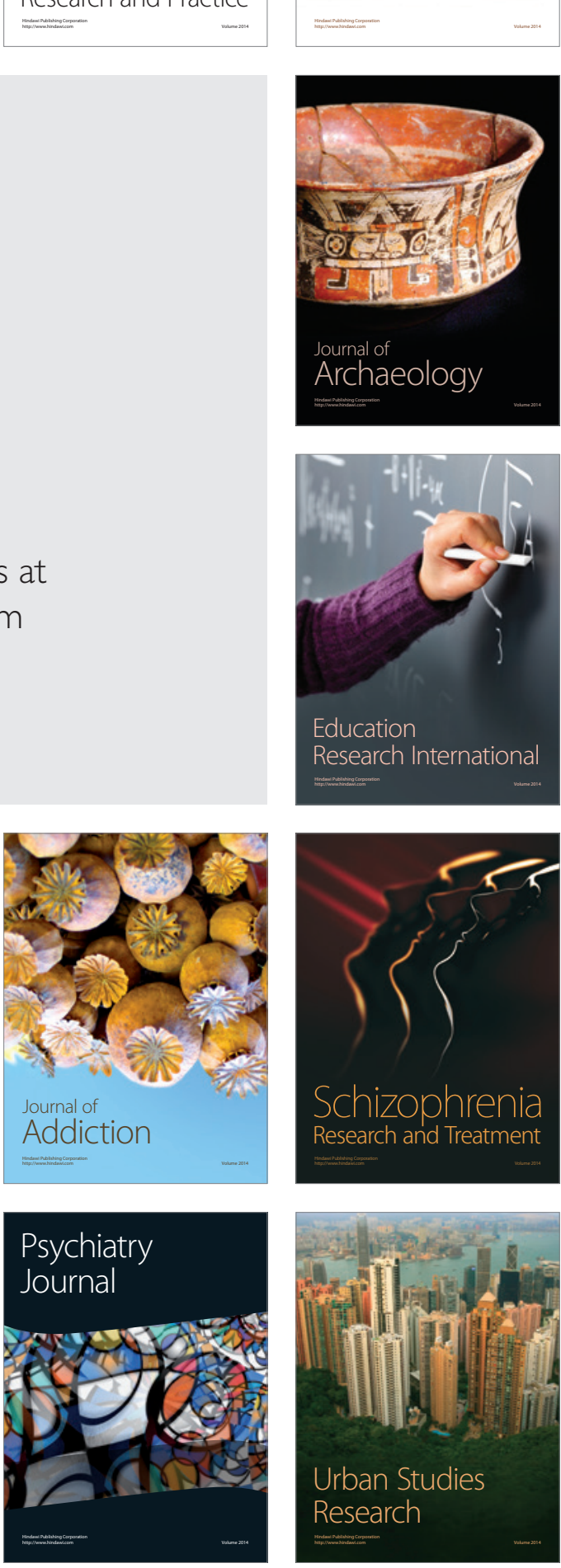